Lexis Vol. XLIII (1) 2019: 5-54

\title{
La voz indio en textos americanos de 1494 a 1905 Un acercamiento gramatical a la historia conceptual*
}

\author{
Concepción Company Company \\ Universidad Nacional Autónoma de México
}

\section{RESUMEN}

Este trabajo analiza la voz indio en documentación americana escrita en español de 1494 a 1905. Examina cómo fue conceptualizado el indio por quienes escribieron esos documentos, qué nos dice la sintaxis de cómo eran las relaciones entre el indio y otros actores de la sociedad americana, qué papel tuvo el indio en la vida cotidiana de ese espacio geográfico y cuáles fueron los cambios conceptuales, reflejados en la sintaxis y en la semántica, producidos a lo largo de esas cuatro centurias en torno a esta voz. El artículo estudia la voz indio desde diversas variables independientes, sintácticas y semánticas, tales como la cuantificación diacrónica general de aparición de la voz; el soporte textual y el tipo textual en que preferentemente se documenta la voz; la comparación con otras voces identitarias de Hispanoamérica, como español; la aparición o no de cuantificadores determinando a indio; el grado de individuación con que esta voz aparece; la identificación y calificación de los referentes denotados mediante indio, así como las clases semánticas de verbos concurrentes con la voz.

Una versión preliminar y abreviada de este trabajo fue leída en el congreso 21 Hispanistentag, celebrado en Múnich en marzo de 2017. Agradezco a Virginia Bertolotti y a Ascensión Hernández Triviño el diálogo y los comentarios críticos a una primera versión de este texto.

https://doi.org/10.18800/lexis.201901.001 
De todas ellas se infiere una fuerte asimetría social y el rango inferior de los referentes de esta voz; se observan, asimismo, cambios estadísticamente significativos, sobre todo, en el siglo XVIII.

Palabras clave: indio, sintaxis histórica, semántica histórica, formas de tratamiento, historia conceptual

\section{AbSTRACT}

The paper analyzes the word indio and the concepts underlying it, in American documents from 1494 to 1905 written in Spanish. The paper examines the syntax, the semantics and the contexts in which indio appears, to shed light on the relationships between indio and other actors of the American society, like español, and to shed light on the conceptual changes along 400 years. The paper analyzes various independent syntactic and semantic variables; for instance, the general frequency of the word during four centuries, the textual genre in which indio preferably appears, the quantification, the individuation, and the semantic classes of verbs. In all variables, it is clear a strong social asymmetry for indio and the low social class status that indio had always in Spanish America. There are some important grammatical and conceptual changes in the $18^{\text {th }}$ century.

Keywords: Indian, historical syntax, historical semantics, address forms, history of concepts

\section{Introducción y objetivos}

La voz indio, junto con otras como naturales, indígena, esclavo, mestizo, negro, español, ciudadano, América, americano, colonia, virreinato, independencia, patria, nación, encomienda, pueblo, justicia, ley, derecho, soberanía, constitución y un extenso etcétera, forma parte de un conjunto de términos claves o ejes en la construcción histórica de Hispanoamérica. Sin duda, la cultura construida por los indios de Hispanoamérica, sus lenguas y los muy diversos conceptos e imaginarios asociados a aquella voz han contribuido a otorgar la actual identidad de los 19 países que integran hoy este subcontinente en América. Menos sabido es, sin embargo, cómo aparece codificada lingüísticamente la voz indio en textos virrei- 
nales e independientes escritos en español, qué papel jugaron los referentes denotados por ella en la gestación de la vida cotidiana de esos países, las tensiones sociales que a través de esa voz afloran en los textos antiguos y las ideologías que subyacen a tales tensiones.

Este trabajo se inserta en el vértice de dos disciplinas generales, lingüística histórica e historia de los conceptos. Tiene como objetivo esencial analizar la otredad, que en el caso que nos ocupa es, centralmente, el indio. Esto es, me propongo examinar cómo se conceptualiza el 'otro' desde la palabra de quienes escribieron en América, fueran estos españoles — criollos o peninsulares-, extranjeros o los propios indios, si bien, como es sabido, la escritura de indios en español es prácticamente inexistente en la documentación de los fondos documentales históricos americanistas. ${ }^{1}$

En el marco de la primera disciplina, lingüística, este texto se ancla, a su vez, en dos disciplinas, en filología, la disciplina que, como es sabido, busca en los textos, orales o escritos, la cultura e identidad de un pueblo, y en sintaxis, la disciplina que analiza cómo se combinan y se disponen linealmente las formas de una lengua y cómo, a través de esas combinaciones, puede manifestarse la simbolización del mundo de los actores de los textos. La lengua es, en última instancia, la codificación de los significados de un pueblo, de manera que existe una estrecha relación, entre lengua, cultura y visión de mundo. El análisis lingüístico puede arrojar información relevante sobre la historia, la cultura y los conceptos que se construyen en y con lengua, la española en este caso. Se trata de una codificación altamente simbólica y abstracta, requerida siempre de contexto, filtrada por convenciones sociales seculares y por la arbitrariedad que rige y moldea la estructura de cualquier lengua. En el marco de la segunda disciplina, historia, el trabajo pretende

\footnotetext{
1 Sin duda, como es sabido, desde el siglo XvI hay notables excepciones y existen crónicas y otros tipos de textos escritos por indígenas y mestizos, tales como el cronista mestizo don Fernando de Alva Ixtlilxóchitl, que vivió a caballo entre los siglos XVI y XVII en el centro del actual México, o los cronistas indios Pachacuti y Huamán Poma en el actual Perú, pero considero que son excepciones en el conjunto de la producción escrita literaria y no literaria virreinal americana.
} 
aportar, desde el análisis lingüístico, información sobre los conceptos asociados a una voz nuclear para la construcción identitaria americana, indio, y mostrar que no existe una relación unitaria ni simple entre ideología, cultura y lengua, sino que este vínculo es multiangular y complejo, al menos cuando se aborda esta voz. En suma, este artículo se encuentra en la línea de otros trabajos sobre lengua e ideología, en el sentido de Hodge y Kress (1993) o Dirven, Hawkins y Sandikcioglu (eds., 2001), y sobre historia y conceptos que han sido clave en la gestación histórica de un país, en el sentido del Diccionario político y social del mundo iberoamericano, conocido como Iberconceptos I (Fernández 2009a).

Hasta donde sé, la voz y concepto indio no han sido trabajados desde la lingüística ni desde la diacronía de la lengua, vía el examen de los contextos en que esta voz aparece. Sí lo está, con otra mirada, desde la historia, desde la antropología, desde la etnología y desde la filosofía. Esta voz, y los conceptos a ella asociados, tampoco están abordados en el diccionario arriba mencionado, al menos no en esta primera etapa del proyecto; aparece mencionada muy de pasada en la introducción de la entrada “América” (Feres 2009). Por ello, la información que arroje este primer acercamiento lingüístico puede ser complementaria de la de otros trabajos construidos desde otras perspectivas disciplinarias. En suma, pretendo poner en relación lengua e ideología, apoyada en los marcos y metodología de la filología tradicional y de la lingüística histórica.

El objetivo general es analizar cómo fue conceptualizado el indio por quienes escribieron la documentación americana, qué nos dice la sintaxis de cómo eran las relaciones entre el indio y otros actores de la sociedad americana, qué papel tuvo el indio en la vida cotidiana de este espacio geográfico en el periodo que va de 1494 a 1905 y cuáles fueron los cambios conceptuales, reflejados en la lengua en torno a esta voz, producidos a lo largo de estas cuatro centurias.

El objetivo específico es analizar, como dije, la voz indio en su sintaxis y su semántica, atendiendo a dos conjuntos de variables independientes: a) externas: cuantificación diacrónica general de aparición de la voz en un conjunto muy amplio de textos ameri- 
canos; el soporte textual y el tipo textual en que preferentemente aparece la voz; la comparación con otras voces identitarias de Hispanoamérica, tales como español, y la asimetría social que deriva de los diferentes modos lingüísticos con que aparecen referidos indios y españoles; $b$ ) internas: la aparición o no de cuantificadores determinando a indio; el grado de individuación con que esta voz aparece; la identificación y calificación de los referentes denotados mediante indio; los contextos semánticos de aparición, las clases de verbos concurrentes y la relación que la voz contrae con estos verbos. Llamo externas al primer conjunto de variables, porque abordo en ellas cuantificaciones generales del corpus base del análisis y planteo las inferencias conceptuales que es posible extraer de aquellas; llamo a las segundas, internas porque ellas constituyen el análisis sintáctico específico de la voz indio, sintaxis que va acompañada siempre de numerosa información semántica y pragmática.

El trabajo arroja luz, según creo, sobre aspectos importantes de ideología e historia conceptual en torno a esta voz. Por ejemplo, resulta patente que existe una tensión ideológica constante entre ignorancia y aceptación del otro, entre control y aparente libertad del otro, entre desigualdad y aparente igualdad del otro. En el caso que nos ocupa, el indio es el otro, pero también lo es el español, ambos constituyen la otredad, los 'otros' de manera recíproca, aunque veremos que existen también diversos otros asociados al indio, sintáctica y conceptualmente. ${ }^{2}$ Tal tensión está latente en cualquier estudio de ideología lingüística (Hawkins 2001), ideología entendida, como es sabido, como un cuerpo sistemático de ideas

\footnotetext{
2 Para algunos historiadores de las ideas y de la sociedad virreinal americana, en particular Alberro y Gonzalbo (2013: 14-17), los conceptos 'grupo', 'otro', 'otredad', 'ellos', los no españoles, frente a 'nosotros', españoles, es un invento de historiadores y sociólogos del siglo xx, resultado de un proceso de investigación, que dista de reflejar una distinción social real en la América colonial. Sin duda, toda taxonomía y análisis es resultado de un proceso de investigación, no obstante, los datos del corpus base del análisis sí indican que los indios, fuera cual fuera el lugar geográfico americano, eran vistos por los españoles como otros y grupalmente, con escasa individuación, y a su vez los indios veían a los españoles como otros, ambos 'otros' debían constituir parte de los muchos otros que construyeron las actuales sociedades hispanoamericanas.
} 
organizadas alrededor de uno o varios ángulos, ejes o puntos de vista e ideas que moldean experiencias y expectativas sobre la interacción social de los hablantes dentro de determinados marcos de referencia y de coordenadas espacio-temporales condicionantes de tal interacción (Hodge y Kress 1993: 6). En la voz que abordaré, son los puntos de vista plasmados por quienes escribieron o dictaron documentos en español en América. Examinar, entender y explicar cuáles son las dimensiones o ámbitos de tales ideologías y tensiones es pertinente para un análisis lingüístico.

Se hace patente, asimismo, a través del análisis, que "la realidad social está lingüísticamente constituida” y que "lenguaje y realidad son pues dos caras imprescindibles de la misma moneda: el lenguaje es parte - y parte sustancial— de la realidad y la realidad sólo puede ser construida, aprehendida y articulada a través del lenguaje”, como señala Fernández (2009b: 26-27). Examinar la dialéctica entre los lugares sintácticos de aparición de la voz indio y la compleja y multiangular semántica conceptual asociada a ellos, así como entre la voz misma y sus contextos de aparición, probará, sin duda, que cualquier realidad está lingüísticamente construida.

Este trabajo, además de esta breve introducción, está organizado en siete apartados. La sección $\$ 2$ está dedicada a describir brevemente el corpus base del análisis y los criterios cuantitativos de selección para llevarlo a cabo. En \$3, a manera de antecedentes, reviso someramente el tratamiento lexicográfico de la voz indio en algunos diccionarios de la lengua española, para mostrar que en todos ellos se hace explícita la estigmatización y el clasismo de que han sido objeto los referentes aludidos con esta voz, información que no tiene nada de novedosa, pero que es de interés en tanto que los diccionarios recogen la sedimentación de usos seculares, y en ellos se puede apreciar cómo la diacronía de una lengua siempre deja huellas en la sincronía asentada en un diccionario. El apartado \4 expone el contexto histórico general de la voz y propone, a partir de la documentación, dos etapas generales en la conceptualización del indio. La sección \5 expone la diacronía general cuantitativa de la voz indio y contrasta esta con español, en cuanto a formas de tra- 
tamiento, en cuanto a algunos contextos de aparición conjunta de ambas voces y en cuanto a los soportes textuales y clases de textos en que se concentra la voz indio. El apartado $\$ 6$ está dedicado a presentar algunos aspectos de la sintaxis, la semántica, así como los contextos de aparición de la voz objeto de análisis. Cierran unas conclusiones en $\$ 7$, que son tanto un breve resumen de lo expuesto, como algunas generalizaciones de interés para la relación entre lengua, cultura y sociedad.

\section{El corpus}

La información está obtenida del Corpus Diacrónico y Diatópico del Español de América (CORDIAM), de la Academia Mexicana de la Lengua, que es de libre acceso: www.cordiam.org.

El CORDIAM contiene, en el momento de cerrar este artículo (enero de 2019), 9163 textos, distribuidos en 4709 documentos de archivo, 3779 textos de prensa y 675 obras de literatura, que suman un total de 6,435.906 millones de palabras. Es un corpus con una profundidad histórica de 400 años: el primer documento corresponde a 1494, el último a 1905. Abarca los actuales 19 países de Hispanoamérica, más Jamaica, Trinidad y Tobago, Belice, Guyana y parte de Estados Unidos, ya que fueron territorios de la corona española en América; esto es, contiene datos de 24 actuales países de América. Está estructurado en tres subcorpus, CORDIAM-Documentos, CORDIAM-Literatura y CORDIAM-Prensa, y contiene una tipología textual ad hoc para cada uno de los subcorpus, realizada a partir de las características propias de los textos (Bertolotti y Company en prensa). Permite búsquedas globales o por subcorpus, sean cronológicas, sean por país, acorde con la distribución política actual de Hispanoamérica, sean por tipo de texto, pero también permite búsquedas parciales, sea por siglos o intervalos, desde un año a un lapso mayor, sea por un solo país o por varios, en la selección $\mathrm{u}$ orden que solicitado por el investigador, sea por tipos y subtipos textuales, uno, varios, y por cruces de tipos textuales. Permite búsquedas léxicas simples pero también búsquedas discontinuas y 
complejas de tipo gramatical. Proporciona cuantificación de palabras y de textos en los que se ha documentado una determinada búsqueda.

Es un corpus caracterizado por una alta fidelidad filológica, ya que todos los documentos han sido extraídos directamente de archivo y transcritos por filólogos en paleografía estrecha, con la mínima manipulación indispensable para evitar pérdida léxica en el motor de búsqueda. Los periódicos, cuando no estaban disponibles digitalmente, fueron extraídos de las hemerotecas correspondientes y fotografiados; las imágenes todas fueron convertidas a texto y este fue cotejado cuidadosamente con su correspondiente imagen. Las obras literarias son o bien ediciones realizadas por filólogos o bien ediciones críticas ya disponibles o bien, en caso de no existir las dos primeras, el CORDIAM selecciona las ediciones príncipe, en los tres casos fueron sometidas al mismo tratamiento que los periódicos.

El CORDIAM tiene ciertas propiedades específicas que lo hacen un instrumento idóneo para el tipo de análisis que planteo. Contiene solamente textos escritos en América y en un $90 \%$ o más, escritos por nativos de este continente. Incorpora una plantilla de metadatos asociada a cada documento, que se despliega en cada búsqueda, y es posible hacer búsquedas por seis de los parámetros de los metadatos; permite ver el documento o texto completo y bajarlo a una computadora; genera, además, una base de datos en automático, si así lo desea el investigador.

La búsqueda de datos, soporte de esta investigación, fue cerrada el 14 de marzo de 2017, cuando el CORDIAM contenía 5270 textos, de los cuales 4178 pertenecían a CORDIAM-Documentos, 1077 a CORDIAM-Prensa, y 15 a CORDIAM-Literatura, en un universo de 4.180.425 millones de palabras. Es pertinente esta aclaración porque buena parte del análisis cualitativo está respaldada por análisis cuantitativo y estadístico, y los números que arroja el CORDIAM difieren sustancialmente entre marzo de 2017 y el momento actual (enero de 2019).

Realicé una búsqueda de la voz indio en todas sus grafías posibles: indio, yndio, jndio, indyo, indjo, yndyo, yndjo, tanto con flexión de 
género, masculino y femenino, como de número, singular y plural; no está documentado *jndjo en ninguna de sus flexiones.

La búsqueda de las ocho voces arriba indicadas muestra que la grafía más común, por mucho, hasta bien entrado el siglo XVIII es yndio, tanto en singular como en plural, en masculino o femenino; la actual indio empieza a generalizarse en el XVIII en la prensa. Tal variedad de grafías es síntoma de que el referente 'indio’ era una realidad nueva que requería ser nombrada, y por ello no estaba sedimentada una sola escritura. La multiplicidad de grafías es reflejo, asimismo, de que hasta 1743, fecha de la primera ortografía académica, no existió como se sabe, una ortografía reguladora, normativa y unificadora de los diversos usus scribendi. Tal número de variantes gráficas puede ser puesta en relación, en última instancia, con el hecho bien conocido de que una entidad necesita ser nombrada para entrar a la existencia, aspecto filosófico planteado en muchas cosmovisiones, como, por citar un solo caso, en la judeocristiana: "en el principio fue el verbo" (Juan 1: 1), y con el hecho, asimismo ya estudiado, de que designar mediante un nombre confiere un orden al mundo que rodea a los seres humanos y a los asuntos humanos en general (Taylor 1989: 6).

Para tablas y metalenguaje emplearé la grafía actual indio, pero los ejemplos respetan íntegramente las grafías de los documentos y textos subidos en el CORDIAM; he quitado tanto las cursivas, resultantes del desatado de abreviaturas, como indicaciones de cambio de foja y de línea en un documento, para hacer más fluida la lectura. La referencia entre corchetes en los ejemplos señala en primer lugar el año a que corresponde el testimonio, seguido del país al que pertenece tal testimonio, según la actual división política de Hispanoamérica. Dado que la mayor parte de ejemplos procede del subcorpus CORDIAM-Documentos, no indico el tipo de documento en el corchete de referencia - jurídico, administrativo, cronístico, cartas-, salvo que sea pertinente para el análisis de algún aspecto. Cuando los ejemplos proceden del subcorpus CORDIAM-Prensa, señalo que se trata de prensa en la referencia, así como el nombre del periódico. 
Respecto a la voz indígena, esta sólo tiene cinco documentaciones, a la fecha, en el CORDIAM, todas muy tardías, finales del siglo XIX, la primera de las cuales aparece ejemplificada en (1a). Por esta razón empleo indio a lo largo del trabajo. La primera documentación de indígena como sinónimo de 'persona, lugar u objeto originario de las Indias occidentales’ es bastante tardía, 1770, según indica el Corpus Diacrónico del Español (CORDE) de la Real Academia Española (www.rae.es), ejemplificada en (1b). ${ }^{3}$ Esta voz no aparece en el corpus del Nuevo diccionario bistórico de la lengua española de la Real Academia Española. A todo lo largo del siglo XIX se sigue documentando indígena en el sentido de 'natural' u 'originario' de un lugar, en concurrencia, frecuentemente, con indio, como se aprecia en (1c). El uso común actual de indígena como eufemismo de indio no está atestiguado en el siglo XIX en el CORDE. ${ }^{4}$ La voz natural, casi siempre en plural, naturales, ejemplos en (2), y muchas veces en concurrencia con indio, (2a), era uno de los modos usuales, como se sabe, de referir a indio, particularmente a finales del siglo XV y buena parte del XVI en la documentación colonial; existen numerosas documentaciones en el CORDIAM de natural, pero su valor, así como sus posibles semejanzas y diferencias con la voz indio está fuera del objetivo de este trabajo.

(1) a. Sabido es que los naturales del Perú poseían algunos eficaces medicamentos contra varias enfermedades, ignorados entónces por los médicos europeos, como, por ejemplo, la quina, cuyas propiedades febrífugas fueron descubiertas por un indígena á

\footnotetext{
3 El mismo carácter tardío está referido por los historiadores (Mazín 1999: 11; Ramírez 2011: 1643) para esta voz, postrimerías del siglo XIX y siglo XIX, si bien Ramírez (2011: 1645) indica que "la palabra latina indígena apareció por primera vez en el año de 1492 en el Diccionario de Elio Antonio de Nebrija, bajo la acepción 'natural de allí. Esta noción vuelve a aparecer en las ediciones de 1545 y 1581 pero ahora como 'varón o muger natural de allî’; todavía en esos años no se podía considerar el término como sinónimo de la expresión indio de América”.

4 Para algunos historiadores (Ramírez 2011: 1644), indígena es "expresión que busca borrar las diferencias sociales que habían predominado en el antiguo régimen, según calidad y limpieza de sangre, para conseguir la tan ansiada homogenización [por parte de los intelectuales] de la sociedad".
} 
un español [1877, periódico El negro Timoteo, Uruguay, CORDIAM]

b. le diré que nuestro Cácota de Suratá no se encuentra en los mapas; es una población indígena, a dos días de distancia de la Pamplona americana [José Celestino Mutis, Carta a Carlos Linneo, 1770, Colombia, CORDE]

c. La mayor parte del indígena se ha aniquilado, el europeo se ha mezclado con el americano y con el africano, y éste se ha mezclado con el indio y con el europeo [ $\mathrm{S}$ i m ó n Bolívar, Discurso de Angostura, 1819, Venezuela, CORDE]

(2) a. Antes que os hagays a la vela con mucha deligençia mirareys todos los navios de vuestra conserva e ynquirireys e hareys buscar por todas las vyas que pudierdes sy llevan en ellos algun yndio o yndia de los naturales desta isla [1518, Cuba, CORDIAM] b. que todos los naturales de la dicha çibdad e otras gentes se alçaron contra los españoles [1520, México, CORDIAM]

Para varias partes del trabajo, y con el fin de controlar las correlaciones cuantitativo-cualitativas de las variables independientes, establecí un subcorpus, consistente en seleccionar las primeras 300 documentaciones de indio para cada siglo, sin importar la grafía, y las primeras 300 de india, asimismo en cualquier grafía. Separo masculino de femenino porque hay una sintaxis, contextos y tratamiento distinto. De hecho, para los siglos XVI y XVIII las documentaciones en femenino no llegan a los 300 ejemplos en todo el siglo, 243 y 286 casos, respectivamente, mientras que son miles los ejemplos de la voz en masculino en cada uno de esos siglos. En el siglo XV no hay documentación alguna en femenino y sí hay testimonios, aunque pocos, en masculino. En el siglo XVI, las primeras 300 documentaciones de indio o indios se concentran en un escaso lapso de poco más de diez años, 1518-1529, mientras que las 243 documentaciones de india o indias en este siglo requieren de casi todo el siglo, 1518-1599; y algo similar sucede en los otros siglos examinados: muchísimos ejemplos en masculino, pocos, aunque 
no escasos, en femenino. La voz indio está documentada desde el documento más temprano del CORDIAM, 1494, mientras que la voz india es casi tres décadas posterior, 1518. Todo lo cual nos remite a que fue el indio, el hombre, el actor principal de la construcción americana, al menos aquella que queda reflejada en los textos del CORDIAM, ${ }^{5}$ y esta desproporción nos remite también a que la voz en femenino, a diferencia de la masculina, no requería ser codificada lingüísticamente, aunque los referentes de ambos sexos estuvieran presentes desde el inicio de la Conquista. Emplearé en texto la forma masculina singular indio para referirme tanto a hombres como a mujeres, tanto a individuos como a empleos genéricos; he ejemplificado tanto en masculino como en femenino, cuando era pertinente para el análisis cualitativo.

\section{El significado de 'indio' en los diccionarios}

Puesto que este trabajo aborda la sintaxis, semántica y pragmática de una palabra, es pertinente revisar el tratamiento lexicográfico que esta voz ha recibido. He analizado un pequeño grupo de diccionarios académicos, desde el primero, Autoridades (1726-1739), hasta la última versión impresa del Diccionario de la lengua española, realizado por la Real Academia Española y por la Asociación de Academias de la Lengua Española (2013). Excepto en las acepciones neutras de 'originario americano', todas las locuciones y expresiones del conjunto de diccionarios académicos indican que esta voz ha rebasado el ámbito referencial etimológico y con ella se remite, mediante extensiones metafórico-metonímicas, a cualquier persona cuyo comportamiento transgrede el usual o el esperado en una determinada sociedad.

El Diccionario de Autoridades (RAE 1726-1739/1990: s.v. indio) contiene dos acepciones, una que puede ser calificada de neutra y otra que no lo es: 1. "El natural de la India, originario de aquellos

\footnotetext{
5 Será motivo de otro trabajo hacer una comparación del papel que hombres y mujeres indígenas jugaron en la construcción hispanoamericana a lo largo de estos 400 años.
} 
Reinos, hijo de padres Indios”; en esta definición, la mención India en singular es ambigua, pero dado que se ejemplifica con las Leyes de Indias y con los Comentarios reales del Inca Garcilaso, sabemos que esos reinos corresponden a las Indias occidentales, América. En la acepción 2 leemos: ¿Somos Indios?: "Expressión con que se advierte, o redarguye al que juzga, que no le entienden lo que dice, o pretende engañar. Con alusión a los Indios que se tienen por bárbaros o fáciles de persuadir". Hay en esta segunda acepción varios contenidos pertinentes para el análisis, tanto lingüísticos como culturales. Decir no le entienden lo que dice remite, si se toma literalmente, a que hablaban otras lenguas, esto es, 'no entienden la lengua de quien escribe este diccionario', pero tomada en sentido metafórico, que es con el que aparece en Autoridades, significa 'que habla mal y no es comprendido'. Asimismo, la definición de la expresión ¿̇somos indios? significa que ya a inicios del siglo xVIII, y quizá desde mucho antes, había locuciones fijas, frases hechas, que remiten al indio, el 'otro', de forma despectiva, con varias informaciones semánticas, todas peyorativas: una, que el indio pretende engañar, dos, que son bárbaros, esto es, 'no civilizados, acorde con la perspectiva de quienes escribimos este diccionario' o 'no tienen nuestras costumbres', y tres, que son fáciles de persuadir, esto es, son 'poco avispados o carecen del entendimiento usual europeo'.

Con el paso del tiempo, las acepciones peyorativas se han ido acumulando en las sucesivas ediciones de los diccionarios académicos y han crecido exponencialmente las frases hechas discriminatorias, señal de que el indio a lo largo de los siglos ha continuado siendo el 'otro' y de que ha vivido marginado en su propio espacio geográfico, siendo motivo constante de discriminación, sea vía el escarnio, sean otras formas de racismo y clasismo, y que ha motivado, por ello, numerosas acepciones negativas, aplicables a cualquier individuo de una sociedad hispanohablante.

El último Diccionario de la lengua española (RAE-ASAle 2013: s.v. indio, acepciones 3, 6, y locuciones varias) vuelve a mostrar una acepción neutra y muchas peyorativas. Dice: 3. "Dicho de una persona, de alguno de los pueblos o razas indígenas de América"; 
6. "Inculto, de modales rústicos"; 8. Indio de carga: "indio que en las Indias occidentales conducía de una parte a otra las cargas, supliendo la carencia de otros medios de transporte"; Caer de indio: "caer en un engaño por ingenuo"; Hacer el indio: "divertirse o divertir a los demás con travesuras y bromas", "hacer algo desacertado o perjudicial"; Subirsele a alguien el indio: "montar en cólera”. En suma, el indio es equivalente a un animal de carga, porque la lleva cuando no hay otros medios de transporte; es también sinónimo de rústico en modales, ingenuo, ineducado y colérico, señal de que sus modos de actuar debieron ser motivo de sorpresa y escarnio por parte de los otros, de ahí el divertir a los demás de la frase hacer el indio.

El Diccionario de mexicanismos de la Academia Mexicana de la Lengua (AML 2010: s.v. indio) contiene algunas definiciones y expresiones hechas, todas despectivas, como indica la marca de uso que antecede a cada definición: 1 . despect. “persona de modales zafios”. 2. indio pata rajada. despect. "persona indígena o mestiza que vive en zona rural"; 3. No ser indio: "comportarse ineducadamente"; 4. “ ¡Un indio al suelo!”: "Expresa sorpresa por la caída de una persona al suelo".

Finalmente, el Diccionario de americanismos (ASALE 2010: s.vv. india, indio, pp. 1180-1181), que recoge usos de toda Hispanoamérica, tiene dos páginas completas, con una letra de puntaje muy pequeño, en un libro de formato grande, de acepciones y expresiones, todas con marca pop. o desp, esto es, 'popular, no cuidado', 'despectivo'. He aquí un pequeño muestrario: 1. ¡Qué india revuelta!, Guatemala: "Expresa desprecio de lo que alguien dice”; 2. ¡Indio en tierra!, Bolivia: "se usa para indicar que una persona ha sufrido una caída brusca"; "se usa para indicar que alguien se ha quedado dormido por haber ingerido bebidas alcohólicas en exceso; 3. A lo indio, Bolivia, Paraguay, Uruguay: "con brusquedad y rudeza"; 4. Indio con levita, Cuba: "persona de escasa inteligencia, cultura o instrucción”; 5. Indio reculón, Honduras: "persona borracha”; 6. No tiene la culpa el indio (sino el que lo hace compadre), México: "se usa para indicar que se puede salir perdiendo cuando se confía 
en una persona de menor nivel social", y un larguísimo etcétera de acepciones despectivas en todos los países americanos de habla española.

En resumen, solo se documenta una definición neutra, "nativo de América”, y decenas de significados despectivos asociados a la voz indio, sola o en construcciones fijas, en forma de locuciones de diverso tipo gramatical, particularmente, sustantivas, verbales y adverbiales, y en forma de expresiones o frases hechas. Como ya señalé, los diccionarios tan solo recogen la sedimentación de usos seculares, que debieron estar vivos en las sociedades hispanohablantes desde los primeros poblamientos en América, y, al parecer el indio siempre fue el 'otro', y desde siempre fue considerado un ser inferior, un conquistado motivo de desprecio, escarnio y discriminación de diverso tipo. Desde el punto de vista lingüístico, el hecho pertinente que debe ser enfatizado es que la diacronía de una lengua y los usos sociales centenarios siempre dejan huellas en la sincronía, en este caso, la asentada en los diccionarios.

\section{El contexto histórico general de indio en el CORDIAM}

Consideradas globalmente las documentaciones de indio, es posible delimitar dos grandes periodos, cuya línea divisoria cronológica no es estricta, como es lógico, en cuanto a la conceptualización del referente de esta voz a lo largo de los cuatrocientos años que abarca el corpus. Un primer momento calificable de choque profundo, en lo cultural, lo social y en la visión de mundo, que no tiene una cronología paralela en todos los actuales países hispanoamericanos, ya que tal choque se hace explícito, por ejemplo, mucho más tempranamente en el virreinato de la Nueva España que en el del Perú, acorde con la documentación del CORDIAM. Este primer periodo va desde los primeros encuentros y poblamientos de españoles hasta finales del siglo XVII o muy primeras décadas del XVIII, según las zonas. El segundo periodo corresponde a una cierta integración del indio, al menos desde la perspectiva de los criollos que escribieron los textos, y abarca los siglos XVIII y XIX, integración 
que tampoco es homogénea geográficamente. Estos dos grandes periodos aparecen resumidos en la tabla 1 a continuación. Los incisos de letras no corresponden a sucesiones conceptuales cronológicas necesariamente; pueden serlo en ocasiones, pero pueden también corresponder a simultaneidades conceptuales a lo largo de los casi 200 años de cada periodo.

\section{Tabla 1}

Concepto e imagen de indio en la diacronía del CORDIAM

\begin{tabular}{lll}
\hline 1. Siglos XVI-XVII: & $\begin{array}{l}\text { Choque } \\
\text { profundo: }\end{array}$ & $\begin{array}{l}\text { a) Extrañeza } \\
\text { b) Enfrentamiento y resistencia } \\
\text { c) Sometimiento, explotación y exclusión }\end{array}$ \\
\hline 2. Siglos XVIII-XIX: & Integración: & $\begin{array}{l}\text { a) Incorporación a la vida cotidiana pública } \\
\text { b) Continuación de asimetría social }\end{array}$ \\
\hline
\end{tabular}

En el primer periodo, el choque cultural y extrañeza debieron ser tan impactantes en la vida del nativo americano, que todavía en 1600 un cronista peruano, Pachacuti, nos dice que agora daba la vuelta el mundo, como se ve en el ejemplo de (3a) abajo. León-Portilla (1993: 20) apunta que más de un buebuebtlabtolli, 'expresiones de la antigua palabra', del Códice Florentino, siglo XvI, habla de “extraños personajes por el rumbo del oriente, venidos del más allá de las aguas inmensas”, expresión que, según el autor, debe enmarcarse en la antigua tradición acerca del retorno de Quetzalcóatl. Esta tradición se ve apoyada en el ejemplo de (3b), que hace explícita la idea de la inmortalidad de los nuevos extraños que llegaron a tierra americana.

(3) a. auia Dios uençido a las guacas y los españoles a los yndios; enpero que agora daua la buelta el mundo [1600, Perú, CORDIAM]

b. porque antes pensavan eran inmortales y huyan duzientos o trezientos de uno o dos de cavallo [1525, México, CORDIAM]

Desde muy temprano, ejemplos de (4), se documentan asimismo numerosos ejemplos de resistencia de indios contra españoles, con 
la correspondiente toma de conciencia de que estos eran simples humanos; estos ejemplos, como los anteriores de (3), no son sino otra manifestación del choque cultural que construye este primer gran periodo, y que queda reflejado a cabalidad en el CORDIAM.

(4) a. y agora aconteçe atenerse un yndio con un christiano que esté a pie como él, lo que antes no hazian [1525, México, CORDIAM]

b. vanlo tomando y veen que tanbien muere el christiano y el cavallo de un golpe o lançada, como ellos [1525, México, CORDIAM] c. y que, quando el marqués entró en esta tierra... y que Dios y los españoles quedarían vençidos desta uez, y todos los españoles muertos [1600, Perú, CORDIAM]

La extrañeza debió ser recíproca, sin duda, tanto del indio hacia el español como por parte de este hacia aquel. Los ejemplos de (5) abajo son de los pocos casos del CORDIAM de los inicios del primer periodo, en que se describe la extrañeza y sorpresa que el indio y sus costumbres causaban. Es muy sintomático que sean ejemplos prácticamente aislados en un corpus con miles de documentaciones de indio ya en el siglo XVI. Dado que la ausencia de testimonios puede ser tan significativa como la presencia — si extendemos el sentido de "signo cero” de Jakobson (1971 [1939]) a este análisis: la ausencia comunica tanto como los signos lingüísticos presentes-, es posible inferir que el español mostró siempre desinterés conceptual por el otro, el indio, al menos en la amplia documentación contenida en el corpus.

(5) a. non avya fallado personas en la costa de la mar que le supiesen dar çierta relaçion dello porque heran todos gente desnuda que no tyene bienes propios ni tratan ny van fuera de sus casas ni otros vienen a ellos, segvnd dellos mesmos supo [1494, República Dominicana, CORDIAM]

b. que, çierto, fue de notar porque... copia de spañoles a cavallo y a pie, y mucha cantidad de jndios que salieron a los resçibir con sus divisas y plumajes e ynstrumentos, baylando y cantando [1529, México, CORDIAM] 
Los ejemplos de (6) abajo reflejan, en cambio, el tenor generalizado de la relación español-indio, con expresiones como hacer prisión, haber a las manos 'prender', cobardes, que, con algunas variantes y algunos cambios cuantitativos, aparecerá a lo largo de las cuatro centurias contenidas en el CORDIAM. En suma, los ejemplos de (6) son paradigmáticos de cómo se estableció la relación con el indio desde el inicio de la Conquista.

(6) a. quel dicho Contreras trabaje mucho con él e tenga manera que Cahonaboa vaya a hablar con vos por que mas seguramente se haga su prisyon e por que el anda ndesnudo e seria malo de detenerle, asy vna vez se soltase e se fuyse no se podria asy aver a las manos [1494, República Dominicana, CORDIAM] b. asy desmandados e desconçertados por el mal recabdo que ternian, como estos yndios sean covardes e no dan la vyda a ninguno por puro themor, fallandolos [a los españoles] de dos en dos o tres en tres podrya ser que tomasen atreuimiento de los matar [1494, República Dominicana, CORDIAM]

En este primer periodo de profundo choque, además de la extrañeza, la resistencia y el enfrentamiento ya analizados y ejemplificados, surge otra constante histórica, con abundantes ejemplos de muy diversa procedencia geográfica y variado contenido documental: el sometimiento y la explotación del indio por parte del español, con la consecuente consideración de aquel como un bien mueble que puede ser comprado, vendido, donado, transferido, o como un sometido que debe pagar impuestos y bienes de diversa índole. Los verbos y expresiones tomar, dar, tener, sacar, ser de alguien, hacer pecheros y tributarios, ${ }^{6}$ despojos de guerras, pagas de

\footnotetext{
6 Pagar tributo, de ahí la frecuente expresión indio tributario en la documentación americana, era señal y prueba de que los indios fueron desde el inicio de la Conquista considerados jurídicamente súbditos de la Corona española, lo cual no fue impedimento para que el pago de tributo fuera cada vez más oneroso para ellos y que tal pago fuera de la mano de explotación y sometimiento (Marichal 2017; Obara-Saeki y Viqueira 2017, entre muchos otros), y para que, hasta la fecha, sean "constantes sujetos de despojo, que constituyen el extremo de pobreza y marginación hasta hoy” (León-Portilla 2011). El
} 
tributos, etc. de los ejemplos en (7) constatan el análisis. A estas expresiones, hay que sumar los constantes testimonios que hablan de exclusión, (7d), de posesión, sometimiento y marginación, (7e) - (7h), que aparecen desde muy temprano y que son un caracterizador de este primer periodo.

(7) a. Y si alguno [bienes] tenjan los yndios, ya se lo an tomado en los despojos de las guerras y, despues, en las pagas de los tributos. Tanpoco les está bien a los yndios, porque con poner estos dos diezmos, a todos los azen pecheros y tributarios [1550, México, CORDIAM]

b. y a otros hazia mercedes sacando muchos yndios de sus rrepartymyentos, tributarios de tassa haziendolos yanaconas de sus propios encomenderos que quiere dezir criados de su casa dandoselos por çedulas para que les siruiesen en todos ofiçios de labradores pastores y cauallerizos ortelanos y leñadores [1585, Bolivia, CORDIAM]

c. Señor, ¿qué a de pagar su tributo al pobre yndio y qué lo a de lleuar a su muger y hijos? [1615, Perú, CORDIAM]

d. aunque no son monjas profesas, por ser como son jndias [1529, México, CORDIAM]

e. ni de otro ningun yndio de mi encomienda [1627, Colombia, CORDIAM]

f. por ser como soy del dicho Antonio yndio de las rreclusiones [1663, Chile, CORDIAM]

g. hijo lejítimo de Antonio yndio de la rredusion de Ytata [1663, Chile, CORDIAM]

h. hiso pareser ante si a don Julian Martines yndio de la encomienda del regidor Alonsso Esteuan [1697, Venezuela, CORDIAM]

tributo solía consistir en minerales o productos agrícolas y animales recolectados en las zonas tributarias, tales como oro, plata, quina, coca, grana cochinilla, y un amplio etcétera comercial. 
Es posible que el rápido sometimiento y la posesión de indios hayan estado respaldados por una relación social asimétrica de tutela, de señores y siervos, en el sentido jurídico romano, que debió solaparse con, y en cierta manera reproducir, la jerarquía social vertical estricta que existía en varias zonas del mundo prehispánico, como, por ejemplo, entre nahuas y mexicas, que desde el nacimiento estaban asignados a uno de dos linajes, pipiltin 'señores' o macehualtin 'siervos', sin posibilidad de movilidad social alguna (León-Portilla 1993).

Por lo que respecta al segundo periodo, siglos XVIII-XIX, este está caracterizado por dos aspectos: uno, por una integración del indio en las formas de vida y costumbres de los españoles, ejemplo de (8a), y por la asimilación total a las creencias religiosas de los españoles $(8 \mathrm{~b}) ;^{7}$ nótese que en ambos ejemplos hay una actitud de tutela y protección del español hacia el indio (8a) o de solicitud de ayuda de este hacia aquel ( $8 \mathrm{~b})$, sistema tutelar que se mantiene en el siglo XVIII, como ya señalara León-Portilla (1993) para el periodo inicial. Dos, la constatación de que el indio deja de ser el natural 'nativo', para aparecer incluido en la sociedad multiétnica americana de castas, formando un estamento más, de los más bajos, de la compleja y vertical jerarquía social. Las frecuentes coordinaciones de indio con otras voces que aluden a referentes de castas diversas, zambo, chino, mulato, etc., ejemplos de (9), son prueba de este desplazamiento conceptual: natural / nativo > integrante de una casta. ${ }^{8}$

\footnotetext{
7 Hay diferencias geográficas importantes con correlatos cronológicos. Al parecer cuanto más alejada se encontraba una población de los núcleos administrativos, más tardó aquella en ser asimilada cultural y religiosamente. Por ejemplo, en la Nueva España, según se desprende de los datos del CORDIAM, en el centro del actual México, donde estaba la Audiencia de México, no hay ya juicios por idolatría a mediados del siglo XVII, mientras que en Oaxaca, aislada de la Audiencia de México y aislada de la Audiencia de Guatemala, aunque a ambas audiencias se giraban los juicios y trámites, se documentan juicios por idolatría hasta bien entrado el siglo XVIII.

8 Empleo casta en su sentido lato de sociedad fuerte y verticalmente estratificada; realizo esta aclaración a la luz de lo planteado por Alberro y Gonzalbo en su libro de 2013 (46-48). Para estas autoras, es un error conceptual e histórico considerar que la estratificación social americana colonial correspondía a un sistema de castas, ya que el concepto de 'casta' solo debe ser aplicado a sociedades como la de la India; además, en opinión, de
} 
(8) a. y el buen tratamiento de los Yndios; Y assi se ve todo tan luçido; los Yndios bien doctrinados, vestidos â lo español muchos, y los otros con sus proprios trages muy desentes, como tambien las Yndias en los suios, contentos, y muy consolados por lo que toca â sus curas, en quienes ponen todas sus esperansas de toda su defensa [1703, Paraguay, CORDIAM] b. en donde se allan cautibos los yndios de la nacion Pecuries em poder de los Apaches ynfieles de sus rancherias, pues con ocasion de aver ymbiado a pedir ayuda y socorro don Lorenzo, yndio rincipal y casique desta nasion, pidiendomelo por amor de Dios el que los atendiese como christianos que eran [1706, Estados Unidos, CORDIAM]

(9) a. Supplico se sirua de mandar que las dichas yndia y samba sean castigadas con todo el rigor que combenga para que en ellas sirua de castigo y en otras de ejemplo [ [ $\begin{array}{llll}1 & 7 & 0 & 4 \text {, }\end{array}$ Bolivia, CORDIAM]

b. Defensor nombrado en la caussa de Lucia Yndia y Lucia mulata pressas en la carcel publica por querella [1704, Bolivia, CORDIAM]

Finalmente, en este segundo periodo, empiezan a documentarse con mucha mayor frecuencia que en los siglos precedentes indios implicados en juicios relativos a aspectos diversos de la vida cotidiana, tales como amancebamientos, peleas callejeras, robos $\mathrm{u}$ homicidios entre ellos mismos, como se aprecia en (10), de manera similar a la documentación que es posible encontrar en el COR-

ellas el indio nunca estuvo integrado a un sistema tan vertical y gozaba de cierta libertad para elegir oficio e integrarse a gremios, de manera que las numerosas representaciones plásticas sobre mestizajes y castas representan un estereotipo por demás superficial. Las abundantes coordinaciones en el CORDIAM de la voz indio con voces que refieren a otras razas y mestizajes son, no obstante, indicio de que muy tempranamente aquel dejó de ser conceptualizado como el natural de las Indias occidentales y se movía en los mismos ámbitos sociales que negros, mulatos, cambujos, chinos, saltapatrás, etc., aunque varios de estos, sobre todo los primeros, a diferencia del indio, no tuvieran estatus de súbditos de la Corona. 
DIAM para criollos u otros habitantes americanos. Ello es indicio, a mi modo de ver, de que el indio formaba ya parte integrante de la vida cotidiana pública, y es señal también de que este ya no estaba totalmente separado, o lo estaba menos, en encomiendas y repartimientos, al menos en ciertas zonas americanas. Tal aparente integración no significa, desde luego, que desaparezcan las documentaciones de abuso, de control y de asimetría social del periodo anterior. La historia conceptual para indio es acumulativa, aunque se produzcan cambios notables a partir del siglo XVIII. ${ }^{9}$

(10) a. qué motibo vbo para que matara su hermano, llamado Juanchillo, a otro yndio llamado Lavrian, y dise que estando dicha yndia en su milpa de zandías llego Lavrian y desenterró vna sandía, de lo qual se enojó la india i el yndio, y le dio a la yndia vnos puñetes con vna piedra i la dexo caída [1720, Estados Unidos, CORDIAM]

b. pareció ante mí a una muger detenida en la casa del theniente de alguasil mayor, quien dixo llamarse Juana Ynés, ser yndia natural de la hazienda de Bodenqué y residenta en el pueblo de san Phelipe Guamango. Y preguntádola por el thenor de el antesedente, dixo que abrá tiempo de un año que vino de la juridisión de Selaya y a pocos días de llegada travó ylísita amistad con Nicolás de Santiago, en quién tuvo un hijo llamádose Martín, que éste avrá un mes que murió y que abrá el de dos meses que a que se apartaron del ylísito comersio, aviéndose pedido perdón y arepentidos del pecado que avían cometido [1755, México, CORDIAM]

\section{Variables independientes externas}

En esta sección examinaré cuatro aspectos: 1) la presencia cuantitativa general de la voz indio en el CORDIAM para valorar cómo la información cuantitativa puede aportar información conceptual

\footnotetext{
9 Acumulación conceptual similar esta analizada por Silverblatt (1993) para el indio en la zona andina.
} 
de interés; 2) el contraste cuantitativo de la voz indio con la voz español, así como la asociación de ambas formas a construcciones consideradas gramaticalmente simétricas; 3 ) el tratamiento de respeto, don, doña, aplicado o no a indio, y 4) la manifestación textual de la voz indio en los textos americanos según el soporte textual, documentos o prensa, y según la clase de texto dentro del subcorpus CORDIAM-Documentos, ya que, como veremos, la aparición de indio está significativamente condicionada por el soporte textual y por la clase textual de documento.

\subsection{Indio en la diacronía general del español de América}

Se documentan 11237 ejemplos de indio - singular o plural, masculino o femenino- en 2252 textos de archivo y de prensa. ${ }^{10}$ Ello significa que sólo aparece indio en menos de la mitad de la documentación del corpus establecido (5270 textos) en la fecha de cierre de la base de datos de esta investigación. Eso sí, la voz aparece en todos los países y desde el más temprano documento. Por lo tanto, el indio sí forma parte del mundo y cosmovisión americanos, pero su presencia dista de permear todas las instancias de la vida americana, lo cual, de nuevo, nos lleva a dos conceptos recurrentes asociados a esta voz, a saber, marginación y asimetría social, que, veremos, quedan comprobadas con el análisis de las variables internas más adelante.

La tabla 2 abajo muestra la cronología de las documentaciones de indio en el CORDIAM. La primera columna corresponde al número total de casos por siglo, la segunda, al número de textos por siglo, la tercera, al universo de palabras por siglo, y la quinta presenta una homogeneización de proporciones, con el fin de hacer comparable cada siglo en cuanto a la presencia de la voz y poder apreciar los cambios adecuadamente. Para ello, obtuve por muestreo al azar 5000 palabras en cada siglo, ya que es este el universo de palabras

10 Para efectos del análisis, me pareció adecuado dejar fuera el subcorpus CORDIAM-Literatura, ya que esta puede alterar, con fines estilísticos o poéticos, la sintaxis y semántica de la voz objeto de análisis y las generalizaciones resultantes de la documentación no literaria. 
contenido en el CORDIAM en el siglo XV, e hice un pequeño cálculo de proporciones sobre estas 5000 palabras en cada periodo. Puede apreciarse en la tabla 2 una evolución de la presencia de esta voz en los documentos y textos hemerográficos que, en mi opinión, comporta interés histórico: hay una presencia continuada de indio, aumenta progresivamente en los siglos XVI y XVII, en este último, casi se dobla la aparición de la voz respecto del siglo anterior, pero desciende en el siglo XVIII de forma muy brusca y en el siglo XIX se produce una práctica desaparición de esta voz de la vida escrita, cotidiana y oficial. Por su parte, es relevante señalar que la voz en femenino, india, representa sólo el 10\% (1169/11237) del total de documentaciones; también tiene una presencia continuada, y también "desaparece” de la documentación en el XIX. En suma, la diacronía proporcional de menciones de indio, eliminando decimales, es la siguiente: siglo XV 8 > XVI: 13 > XVII: 23 > XVIII: 8 > XIX: menos de 1 .

\section{Tabla 2}

Diacronía de indio en el español de América (CORDIAM sin literatura)

\begin{tabular}{lllll}
\hline & Casos & No textos & Univ. palabras & $\begin{array}{l}\text { Proporción menciones } \\
\text { en } 5000 \text { pal. }\end{array}$ \\
\hline XV & 10 & 3 & 5646 & 8.8 menciones \\
XVI & 3142 & 1364 & 1186794 & 13.2 menciones \\
XVII & 5833 & 1113 & 1236889 & 23.5 menciones \\
XVIII & 2194 & 1804 & 1268211 & 8.64 menciones \\
XIX & 58 & 986 & 473912 & 0.61 menciones \\
\hline
\end{tabular}

Se desprenden de la tabla 2 arriba una pregunta y una paradoja, para las que, por el momento, apenas tengo una intuición de explicación. La pregunta es la siguiente: ¿la nula presencia de indio en el siglo XIX se debe a que desaparecen de la escena, documental y hemerográfica, por mayor marginación o porque ellos toman en sus manos la construcción del mundo americano independiente y por eso no se nombran a sí mismos? Mi opinión es que desaparecen de la escena escrita. Las independencias americanas fueron llevadas a 
cabo, como se sabe, por criollos fundamentalmente, y ello llevó a una mayor marginación de los habitantes originarios y a un mayor desinterés o ignorancia de aquellos por parte de estos. Indio forma parte de la construcción de la vida cotidiana de los siglos XV-XVIII, particularmente del XVII, pero su presencia en los siglos subsecuentes, como indican los números, se fue haciendo cada vez menor hasta llegar a ser casi imperceptible.

La paradoja corresponde al drástico, e inesperado, decremento de indio en el siglo XVIII. Veamos. En este siglo, como se sabe, se elimina el sistema jurídico de los Austrias de separación de pueblos de indios y pueblos de españoles y se producen fuertes emigraciones de indios a las ciudades, particularmente en la segunda mitad del siglo, a raíz de la implementación de las reformas borbónicas. Y ello tuvo consecuencias lingüísticas (Company 2007): es en el siglo XVIII cuando más indigenismos entran a las variedades americanas de lengua española, porque se generó una convivencia más intensa de indios y criollos; también en este siglo aumentó la frecuencia de numerosas expresiones lingüísticas — construcciones posesivas muy diversas de naturaleza sobrespecificada, impersonales muy diversos también, incremento altísimo de diminutivos de naturaleza pragmática no referencial, entre otras formas gramaticales-, las cuales, aunque de vieja data castellana, debieron activarse por procesos de convergencia comunicativa entre el español y algunas lenguas amerindias, convergencias que se dieron de forma mucho más intensa en el siglo XVIII y no antes. Por ello, es bastante paradójico que la voz indio disminuya drásticamente en el siglo XVIII, ya que, lingüísticamente, es el periodo de significativos incrementos de formas y construcciones, léxicas y gramaticales, incrementos que deben ponerse en relación con la existencia activa de lenguas amerindias, como he expuesto en otros trabajos (Company 1995a; 1995b; 2012).

\subsection{Presencia de indio vs. español en el CORDIAM}

La comparación de la voz indio con español arroja, igualmente, datos relevantes para valorar la historia conceptual de ambas voces en la documentación americanista contenida en el CORDIAM, pero, sobre 
todo, para ubicar la posición de aquel en la estratificación social virreinal y/o colonial. La tabla 3 abajo presenta el número total de apariciones de cada voz en el CORDIAM, el número total de textos en que aparece cada una y la respectiva proporción de cada una por texto. Puede apreciarse en la tabla que indio multiplica casi por seis las apariciones de español, que hay tres veces más cantidad de textos con la voz indio: 2252 de este vs. 814 de español, y que indio dobla a español en el promedio de menciones por texto. Resulta transparente, a mi modo de ver, la interpretación que debe otorgársele a estos números: el que requiere ser nombrado es el indio, el 'otro', mientras que el que escribe y tiene el control de la vida cotidiana y oficial no tiene por qué mencionarse a sí mismo. En consecuencia, es obvio —obviedad bien estudiada desde otras disciplinas - que los españoles peninsulares en el primer siglo y los criollos en siglos posteriores fueron quienes escribieron la documentación —al menos la contenida en el CORDIAM - y fueron estos, y no el indio, quienes construyeron, por tanto, gran parte del actual mundo oficial americano.

Tabla 3

Indio vs. español en el CORDIAM

\begin{tabular}{lccl}
\hline & Casos & Número textos & Proporción de indio por texto \\
\hline Indio & 11237 & 2252 & 4.9 menciones por documento \\
Español & 2131 & 814 & 2.6 menciones por documento \\
\hline
\end{tabular}

La asimetría reflejada en la tabla 3 arriba encuentra apoyo en la sintaxis. Realicé una búsqueda en el CORDIAM de expresiones gramaticales de igualdad: comparativas y coordinadas, del tipo "así $x$ como $y$ ”, “tanto $x$ como $y$ ”, “ $x$ y $y$ ”, “ $x$ o $y$ ”, con indio y español como los miembros de esas cuatro construcciones, en cualquiera de los órdenes posibles de cada estructura. Los resultados de la búsqueda fueron los siguientes: solamente hay siete expresiones de comparativas de igualdad en todo el corpus con español e indio en construcción sintáctica, así españoles como indios, ejemplificadas en (11), de las cuales, en solo una documentación aparece indio como 
primer miembro de la comparación (11c); no hay testimonios de comparativas con "tanto $x$ como $y$ ”. Por lo que respecta a la coordinación copulativa de español e indio, el CORDIAM arroja 39 casos en todo el corpus, español(es) e indio(s), ejemplificados en (12) y no hay documentaciones de coordinación disyuntiva " $x$ o $y$ " con estas dos voces. En las dos distribuciones sintácticas, comparativas y coordinación, los contextos amplios indican, por lo general, desigualdad social, ya que, por ejemplo, con frecuencia se incluye negro u otra etnia-casta tras indio en el contexto, como se aprecia en (11b) y en (12a), además de que los temas todos de los documentos no suelen ser de conciliación ni de igualdad alguna.

(11) a. y los metales muy bajos de ley lo qual tienen por çierto y por espiriençia y lo dizen assi españoles como yndios que los benefician [1581, Bolivia, CORDIAM]

b. cienpre a tenido suspecha y entre ellos no se quieren ni se aman. Cienpre tienen pleyto y mala justicia, ací españoles como yndios, negros en la ciudad [1615, Perú, CORDIAM]

c. sin escusarme a los crezidos gastos para aviarlos, he atendido, proveyendolos de armas, cavallos, bastimentos y lo demas prezisso y nezesario, asi a los yndios como a los vezinos españoles [1706, Estados Unidos, CORDIAM]

(12) a. que la copia de jente que hera no tiene al presente memoria mas de que abia hasta diez o doze españoles e yndios e negros [1556, Cuba, CORDIAM]

b. Siénbrasse en esta ciudad y su jurisdisión trigo y maís, çebada, garbanços y otras legunbres, de manera que corre de ordinario abastesidamente para españoles e yndios [1608, Argentina, CORDIAM]

\subsection{Tratamiento de respeto para indio}

Es sabido que las formas don, doña han sido por siglos tratamientos usuales de respeto en la lengua española. Un modo de matizar la conceptualización del indio en la América virreinal / colonial e independiente en la documentación del CORDIAM es ver cuántos 
indios aparecían con tratamiento de don, doña, y en qué contexto aparecían. Los datos del CORDIAM revelan que este tratamiento casi no se otorga a indio, confirmando la posición social inferior del natural de América y, una vez más, la fuerte asimetría social respecto de indio que se desprende de toda la documentación americanista contenida en este corpus electrónico.

La tabla 4 abajo mide si el tratamiento de respeto don, doña concurre con las voces indio, india, además de cuantificar otras proporciones que me parecieron interesantes, en cuanto que podían arrojar luz para el estatus conceptual y social de indio en la América de habla española. Dado que el CORDIAM permite búsquedas complejas discontinuas, realicé una búsqueda de don + indio, en cualquier posible grafía en masculino y en femenino, con hasta 10 palabras intermedias. Puede verse en la tabla 4 que este tratamiento se aplica a indio en un escaso $1 \%$ del total de documentaciones de esta voz, 130 ejemplos de más de 11000 casos de indio, y puede verse también que don y doña son voces de respeto muy frecuentes en el CORDIAM, casi 16000 ejemplos; es posible, sin duda, que en esos casi 16000 casos de don-doña esté referido algún indio no identificado como tal en el documento en cuestión. Si analizamos la proporción de la forma de tratamiento respetuoso en el total del universo de palabras y en el total de textos, tablas 5 y 6, respectivamente, las cifras son todavía más elocuentes, si cabe, sobre la posición social muy inferior que el indio ocupó en la sociedad americana a lo largo de los cuatrocientos años incluidos en el CORDIAM: 500 veces menos don para indio que para otros actores de la vida americana, tabla 5, una mención de don + indio cada 40 textos, 3 menciones de don por texto cuando los actores no son indios, tabla 6 .

Tabla 4

Tratamiento de don para indio en el CORDIAM

\begin{tabular}{cc}
\hline Don + indio & Otros don \\
$1.1 \%(130 / 11237)$ & 15752 casos \\
\hline
\end{tabular}


Tabla 5

Tratamiento de don para indio en el universo de palabras total del CORDIAM

Universo: 4180425 palabras del CORDIAM: $\begin{aligned} & \text { don }+ \text { indio }=0.00003 \% \\ & \text { don }+ \text { otros }=0.003 \%\end{aligned}$

\section{Tabla 6}

Tratamiento de don para indio en el total de textos del CORDIAM

\begin{tabular}{ll}
\hline En 5270 textos: & $\begin{array}{l}\text { don }+ \text { indio }=1 \text { cada } 40 \text { textos } \\
\text { do } n+\text { otros }=3 \text { en cada texto }\end{array}$ \\
\hline
\end{tabular}

Los ejemplos de (13) abajo corresponden a las primeras documentaciones del tratamiento de respeto para indio e india, respectivamente, en el CORDIAM. Tuvieron que pasar más de 60 años desde el primer momento de la Conquista para que el masculino indio aparezca tratado con don, y más de 100 años para que aparezca el tratamiento de respeto en femenino. Otros tratamientos de don para indio están ejemplificados bajo (14). Particularmente interesante resulta el ejemplo de (14a), de Huamán Poma, en que se reprueba el tratamiento de don para el indio de nivel social bajo por parte de los españoles, porque tal trato de respeto no solo es falso, sino que socava la estratificación social originaria, previa a la llegada de los españoles.

(13) a. juntaronse unos tres prinçipales jndios con el Alonso Ortiz, que se dizen don Joan Xancol y don Hiermo Hastanhua y don Pedro Cacamatl [1556, México, CORDIAM]

b. de do es natural doña Ynes, yndia que truximos de Mexico [1599, México, CORDIAM]

(14) a. a los yndios tributarios le llama "don Juan", “don Pedro" y pónese a comer y conuersar con ellos porque ande al trato o porque están amansebados con sus hijas o ermanas. Y menosprecia y lo echa y destierra a los señores prencipales de 
título. Y ací ay muchos don y doña de yndio baxo mitayo [1615, Perú, CORDIAM]

b. y pasando por la puertta de la casa, donde asistia vn moreno llamado Ambrozio lorenzo reparo que el susodicho estaua dentro, acompañado de un yndio llamado Don Pablo, el qual a oido desir es un yndio de la bega que anda por estos parajes retirado [1708, Venezuela, CORDIAM]

\subsection{Indio según soporte textual}

En este último inciso de variables externas analizo dos tipos de información: por un lado, la frecuencia de la voz bajo análisis contrastando el subcorpus CORDIAM-Documentos con el de CORDIAM-Prensa en el siglo XVIII, ya que es en este siglo cuando surge la prensa en América. Por otro lado, la frecuencia de la voz en el primer subcorpus, comparando las cuatro grandes clases de tipos textuales propuesta para este subcorpus en el CORDIAM.

La tabla 7 a continuación compara la aparición de la voz indio en los dos subcorpus analizados. Queda claro que el indio no es noticia cuando surge la prensa americana: $5 \%$ del total de documentaciones de esta voz en el siglo XVIII, una escasa centena de testimonios, y hay muchos menos casos en la prensa del siglo XIX, solo 5 ejemplos en total, datos que confirman la "desaparición” del indio, ya comentada, de la vida oficial cotidiana, escrita, en América en el periodo independiente. Merece la pena señalar que el indio está mucho menos individuado en la Prensa que en los Documentos: $8 \%$ vs. $41 \%$ de apariciones en singular, respectivamente.

\section{Tabla 7}

Indio en CORDIAM-Documentos y CORDIAM-Prensa. Siglo XVIII

\begin{tabular}{lcc}
\hline & Documentos & Prensa \\
\cline { 2 - 3 } Indio & $95 \%(2095 / 2194)$ & $5 \%(99 / 2194)$ \\
\hline
\end{tabular}

Las menciones en la prensa corresponden, en efecto, no a personas específicas sino al grupo, $y$, en general, un grupo conceptualizado 
como los individuados necesitados de protección (15a), o codificado de manera bastante idealizada (15b), posiblemente lejos de la realidad histórica del siglo XVIII, o un grupo que debe ser culturalmente asimilado o sometido (15c). Los adjetivos concurrentes, pobre, bárbaro, o sin adjetivación la mayoría de indios, más los sustantivos concurrentes, reducción, señas, alegría, son un índice lingüístico de cómo es conceptualizado el 'otro'. En resumen, el indio en la prensa del XVIII proyecta una imagen de paternalismo y tutela, que refuerza la asimetría y posición social inferior aludidas una y otra vez en este trabajo. El indio es un 'otro', y es, además, ajeno y peligroso, debe ser reducido, y es, al mismo tiempo, un sujeto que debe ser protegido y tutelado.

(15) a. se erija la Iglesia de el Hospital mas capaz, y decente, Claustros para los Religiosos, y Enfermerias mas a proposito para los Pobres Indios [1722, México, Gaceta de México, CORDIAM]

b. arrojó á allí á algunos hombres, de los quales acertaron á ser algunos los que saltaron en la Lancha, y conocidos por los Indios, les agasajaron mucho, tomandoles las manos, y hazian señas de alegría [1722, México, Gaceta de México, CORDIAM]

c. El sentimiento y asombro, que naturalmente influyò en los animos de los restantes habitantes de aquel País subceso tan espantoso, se ha mitigado con la esperanza, que se ha concebido de perfeccionar el descubrimiento, y reduccion de algunos Yndios Barbaros [1785, Colombia, Hemeroteca Luis Arango, CORDIAM]

Por lo que respecta a la aparición de la voz indio según el tipo textual dentro del subcorpus CORDIAM-Documentos, los concentrados son estadísticamente significativos, aunque a primera vista pareciera que la voz tiene una distribución textual equitativa. El subcorpus CORDIAM-Documentos contiene cuatro grandes clases textuales de documentos: jurídicos, administrativos, cronísticos y particulares: cartas y notas (Bertolotti y Company 2014). Para evitar 
atomizaciones y valorar mejor los concentrados cuantitativos de la voz, agrupé los documentos jurídicos y administrativos, de una parte, y los cronísticos y particulares, de la otra, como se aprecia en el tabla 8 a continuación. Los 11138 casos del total corresponden a todas las apariciones de indio en el subcorpus CORDIAM-Documentos en los cuatro siglos que abarca este corpus.

\section{Tabla 8}

Indio según tipos textuales CORDIAM-Documentos. Todos los siglos

\begin{tabular}{cc}
\hline Jurídicos / Administrativos & Cronísticos / Cartas-Notas \\
\hline $54 \%(6003 / 11138)$ & $46 \%(5135 / 11138)$ \\
\hline
\end{tabular}

La tabla nos dice que el indio forma parte de los espacios mentales construidos en las cuatro clases textuales, aunque están mayormente concentrados en documentos jurídicos, ejemplos de (16), y documentos administrativos (17). Parece, al menos a primera vista, que las frecuencias están bastante equiparadas entre los dos grandes grupos textuales, mitad en un grupo y mitad en otro, $54 \%$ y $46 \%$, sin embargo, la diferencia de proporciones arrojada por un programa de socio-estadística es significativa, ${ }^{11}$ ya que el estadístico $z$ es $=10.2593, \mathrm{p}<0.05$. Ello nos informa que el indio fue, fundamentalmente, objeto de legislación y regulación de la vida americana, y no fue tanto el tema de la cronística documental y menos aún de las cartas y notas escritas entre particulares, cosa por demás previsible u obvia, aunque ahora los datos lo confirmen plenamente.

(16) a. en la villa de san salvador del bayamo desta ysla fernandina el muy noble señor manuel de Rojas justiçia mayor e Repartidor de los Caçiques e yndios della por su magestad [1534, Cuba, Documento jurídico, CORDIAM]

11 Cf. http://www.socscistatistics.com/tests/ztest/Default2.aspx. La diferencia de proporciones es estadísticamente significativa en este programa cuando $z$ es superior $o$ inferior a 1.96: +/-1.96. 
b. Antes yba con muchos de los soldados desde la dicha çidad de Bariqujçimeto açia la dicha çidad de Burburuata con yntento de castigar con ellos los yndios alçados [1562, Venezuela, Documento jurídico, CORDIAM]

(17) a. y que conforme a las reales cedulas se an de hazer Las yglesias a costa de $\mathrm{Su}$ magestad y de los encomenderos y que los yndios ayuden por su parte [1601, Bolivia, Documento administrativo, CORDIAM]

b. procure no tener En su seruicio ningun yndio ni yndia que no sea por conçierto y salario del corregidor deste partido pagandoselo y dandoles de comer pues de su persona a de començar El buen Exemplo [1602, Venezuela, Documento administrativo, CORDIAM]

El indio aparece muy poco en los documentos y notas escritos entre particulares, aunque hay algunos ejemplos, como los de (18), pero sí es con cierta frecuencia motivo de la narración y actor de los sucesos del nuevo mundo, expuestos en boca de conquistadores y pobladores, y por ello aparece con notable frecuencia en los documentos etiquetados como cronísticos en este corpus electrónico, como se ve en los ejemplos de (19).

(18) a. yendo Pancho casado a misa se enborracho y trabo con vna yndía y andubíeron a Palos y [con] [vn] Piquete en Vn braso donde no se allo el cur[a] ocasion Para quebrarme los ojos [1704, Chile, Documentos entre particulares, CORDIAM]

b. y aquí no hay más dulces que zapotes, por lo que estimaré a v. m. me embíe con estos yndios media arrova de dulces cubiertos; media de colación, que se ponga de anizes gordos y confites [1785, México, Documentos entre particulares, CORDIAM]

(19) a. era forçado hazer primero los caminos por donde passasen con harto trabajo de algunos españoles que para ello yban y puesto que la tierra sea tan aspera como digo esta tan poblada 
de yndios que no puede ser más y toda labrada de conucos y mahizales tienen en sus casas y a la Redonda dellas muchas colmenas de que sacan muy eçelente miel las abejas son muy pequeñas e prietas y no saben hazer mal la çera no es buena porque no la saben sacar y es prieta la miel es muy blanca [1529, Colombia, Documentos cronísticos, CORDIAM]

b. en donde se averiguo no ser ymbasion de enemigos, si solo un acsidente de averse soltado un cavallo en dicha cavallada, con que passado este embaraso determine el dicho dia lunes, dos, despachar a el alferes de miliçia Ambrosio Fresqui, al cappitan Joseph Naranjo, el yndio Pecuri guiador y dos de dicho pueblo de Thaos a descubrir el aguaxe antes que experimentare perder tersera ves el real. Y aviendo salido los dichos, susedioles assi que se perdieron, y perdidos llegaron a la primera rancheria, que los Apaches llaman Tachichichi [1706, Estados Unidos, Documentos cronísticos, CORDIAM]

En resumen, la asociación estadística significativa entre soporte textual y subtipo textual en el interior de uno de los subcorpus permite formular la siguiente jerarquía de mayor a menor presencia de indio en la documentación americana: 1. Documentos jurídicos $>$ 2. Documentos administrativos $>3$. Documentos cronísticos $>4$. Cartas y notas entre particulares $>5$. Textos de prensa.

\section{Variables independientes internas}

En esta sección examinaré cuatro aspectos: 1) la individuación o no con que aparece presentada la voz indio, esto es, si se documenta preferentemente en singular o en plural, ya que la individuación significa que indio adquiere existencia específica y no es simplemente parte de un grupo considerado de modo genérico; 2) si la voz aparece cuantificada o no, de qué tipo es esta cuantificación, y qué significa conceptualmente la presencia de cuantificadores acompañando a la voz; esta variable está gramatical y semánticamente asociada con la anterior, pero constituyen ángulos complementarios; 
3) la identificación del referente aludido con la voz indio y las estrategias gramaticales, de naturaleza adjetiva fundamentalmente, para caracterizar la voz, y 4) los tipos de verbos con que aparece la voz indio, la función sintáctica de esta voz y los contextos en que se inserta la construcción verbo y sustantivo. En algunas de estas variables analizo solamente los tres siglos virreinales / coloniales, XVIXVIII, con el subcorpus de las primeras 300 apariciones en cada siglo; dejo fuera tanto el siglo XV como el XIX, porque la escasa frecuencia de esta voz en el periodo inicial y aún más en el independiente podría distorsionar las generalizaciones, creando sesgos no deseados en la información diacrónica resultante. Adelanto que hay cambios importantes e interesantes conceptualmente, a lo largo de las tres centurias analizadas.

\subsection{Individuación de la voz indio}

La tabla 9 abajo mide si la voz aparece en singular o en plural, indio vs. indios, independientemente de que ambas puedan ir acompañadas o no por adjetivos $u$ otros modificadores y complementos gramaticales. El promedio de singular y plural en los cuatro siglos indica que, en general, el indio fue conceptualizado mayormente como grupo: $77 \%$ plural vs. $23 \%$ singular. Sin embargo, se aprecia un incremento progresivo y sostenido de mayor individuación a lo largo de los cinco siglos: XV $10 \%$ > XVI $14 \%$ > XVII $22 \%$ > XVIII $40 \%>$ XIX $53 \%$, además de que todos los incrementos arrojan significatividad estadística, con $\mathrm{z}=+/-1.96$, al comparar cada periodo con el siglo previo. La voz en femenino, india, aunque no está explicitada en la tabla 9, proporciona una diferencia conceptual interesante respecto del masculino: aparece, en general, mucho más individuada, ya que considerada ella sola presenta tres veces más individuación que el promedio general de la voz en la tabla 9, que incluye tanto referentes masculinos como femeninos; en efecto, el promedio de singular frente a plural de india es $62 \%(720 / 1169)$ vs. $38 \%$ (449/1169), respectivamente, que contrasta, de manera notable, con los promedios de $23 \%$ de singular vs. $77 \%$ de plural, 
ya señalados, de masculino. La mayor individuación de la mujer india nos informa de un aspecto histórico interesante, a saber, que aquella vivió en espacios más pequeños y más cercanos a quienes escribieron la documentación americana, motivo por el cual el término femenino se prestaba gramaticalmente para la individuación, de ahí que aparezca codificada mayormente en singular.

\section{Tabla 9}

Diacronía de singular vs. plural de indio-india

\begin{tabular}{lll}
\hline & Singular & Plural \\
\hline XV & $10 \%(1 / 10)$ & $90 \%(9 / 10)$ \\
XVI & $14 \%(433 / 3142)$ & $86 \%(2709 / 3142)$ \\
XVII & $22 \%(1283 / 5833)$ & $78 \%(4550 / 5833)$ \\
XVIII & $40 \%(869 / 2194)$ & $60 \%(1325 / 2194)$ \\
xix & $53 \%(31 / 58)$ & $47 \%(27 / 58)$ \\
\hline
\end{tabular}

Muchos de los ejemplos ya presentados antes en este trabajo contienen formas en singular de indio e india, por ello no los ejemplifico de nuevo. En cuanto a la manifestación sintáctica en plural, las más comunes, por mucho, son los indios (20abc) e indios (20de) sin ninguna modificación, en ese orden de preferencia. Aparecen también plurales modificados (21), y estos suelen llevar adjetivos bastante diversos, de contenido semántico más negativo que positivo muchos de ellos; se repiten mucho los siguientes adjetivos: naturales, pobres, miserables, putas, hermosas, tributarios, maliciosos, cobardes, infieles, gentiles, cristianos, buenos, enemigos, perpetuos, parciales, sencillos, bárbaros, etc. ${ }^{12}$ También aparecen plurales modificados por frases prepositivas adnominales y oraciones de relativo,

12 Cf. Taylor (1989) para los múltiples adjetivos, positivos y negativos, pero mayormente de estos últimos, con que los curas párrocos del virreinato de la Nueva España calificaban a los indios adscritos a sus respectivas parroquias, a la hora de informar al arzobispo sobre necesidades y vicisitudes de las parroquias en cuestión; tales calificaciones enraizan, como señala el autor, en una larga tradición filosófica sobre el estatus teológico y doctrinal del indio. 
que indican la adscripción o procedencia del grupo, como en (22a), o la actividad u oficio del grupo, (22b).

(20) a. en que existen las minas Ricas y abundantes de Oro que dicen hau[er] en lo descubierto, que en otro tiempo producian Sumas quantiosiSimas, que se auandonaron por las hostilidades de los Yndios [1797, Panamá, CORDIAM]

b. que a de aver mundanças en las Cosas de los yndios con el pareçer destos Religiosos [1518, Puerto Rico, CORDIAM]

c. que de nuevo vienen de otras prouinçias que dexan ya Acabados los yndios que se les dieron [1528, República Dominicana, cordiam]

d. y él mesmo y el adelantado por le tener contento dieron por dos vezes yndios a un hermano del licenciado que truxo consigo [1546, Guatemala, CORDIAM]

e. Y desta causa los amigos de don Hernando andavan tan abatidos y amilanados, y sin jndios porque se los havia el factor quitado [1529, México, CORDIAM]

(21) a. y en mucho perjuyzio de la jurediçión real, e usurpándola, e alborotándola y escandalizando a los yndios naturales desta tierra [1520, México, CORDIAM]

b. se a rreterido (sic) a una c[asa] fuerte temiendose de la vida por las amenaças que los yndios enemigos an mostrado y muestran [1662, Costa Rica, CORDIAM]

(22) a. respondió ella que la enseñaron Petrona Calero y Manuela su hija, quienes avían aprendido de los yndios de yayanizque [1739, Guatemala, CORDIAM]

b. ha visto y oído varias veçes es que su amo don Fernando Alfaro ha tenido enfado con los yndios que ivan de fuera a vender chile, manta y otras cosas [1699, Guatemala, CORDIAM] 


\subsection{Cuantificación de la voz indio}

Un rasgo gramatical del corpus analizado, particularmente a partir del siglo XVII, es que la voz indio aparece modificada con cierta frecuencia por adjetivos cuantificadores, sean cardinales específicos, cinco, cien, mil, tres mil, etc., como se ejemplifica en (23), sean cuantificadores indefinidos indeterminados, muchos, algunos, todos, otros, unos, pocos, demás, etc., como se ve en (24). La razón de esta caracterización sintáctica es, a mi modo de ver, clara: desde el punto de vista de quienes escribieron la documentación americana, españoles y criollos básicamente, se requiere aportar información de cuántos constituyen el 'otro', el indio, bien de manera precisa bien de forma aproximada, porque de tal cuantificación dependen medidas de precaución, prevención o control por parte de los actores españoles o criollos.

(23) a. conviene queden çiento y çinquenta a lo menos çien yndios los mejores para que anden en las obras que vuestra alteza sera seruido hazer en esta isla [1518, Puerto Rico, CORDIAM]

b. y abiendo tenido la dicha ciudad y su distrito al tienpo de su fundasión más de beynte mil yndios, an ydo en disminusión y tendrá el día de oy como cinco mill yndios y los rrestantes se an ydo consumiendo como en las demás partes de Las Yndias [1608, Argentina, CORDIAM]

(24) a. que ningun español les haga ni diga cosa de que resçiban enojo porque metiendose entre vosotros muchos yndios pueden tener çelada para en abraçandose los vnos con vos otros salir los otros e como son muchos podriades correr peligro [1518, Cuba, CORDIAM]

b. A resultado desta yndemoniada ynstructión, que todauía ay algunos yndios e yndias hechiçeros, aunque en poca cantidad que, quando algún yndio o yndia está enferma, los llamauan para que los curen y les digan si an de uiuir o morir [1600, Perú, CORDIAM] 
c. Preguntado... en ellas an concurrido las naçiones de apaches, nauajoes y jutas y apaches de la xicarilla, que a qué fin se hizieron y si concurrieron en ellas algunos otros yndios de los otros pueblos deste reyno, dixo que no saue [1706, Estados Unidos, CORDIAM]

La tabla 10 a continuación, construido con las 300 primeras documentaciones de la voz en masculino en los tres siglos virreinales / coloniales, muestra la frecuencia de aparición de indio con cuantificadores y sin ellos, sean estos cardinales sean indefinidos.

Tabla 10

Diacronía de la asociación de indio a cuantificadores

\begin{tabular}{lll}
\hline & No cuantificación & Sí cuantificación \\
\hline XVI & $84 \%(251 / 300)$ & $16 \%(49 / 300)$ \\
XVII & $72 \%(217 / 300)$ & $28 \%(83 / 300)$ \\
XVIII & $74 \%(222 / 300)$ & $26 \%(78 / 300)$ \\
\hline
\end{tabular}

La tabla informa que, en general, hay más ausencia que presencia de cuantificación con la voz indio, con un promedio de $77 \%$ (690/900) vs. $23 \%$ (210/900), respectivamente. Lo más interesante, sin embargo, son los cambios en la cuantificación y qué nos dicen del concepto e imagen de indio. En la columna de la derecha puede verse que aumentó la cuantificación muy notablemente en el paso del siglo XVI al XVII, $16 \%>28 \%$, pero que a partir del XVII se estabiliza esa sintaxis con una ligerísima disminución de cuantificadores en el siglo XVIII, $28 \%>26 \%$. El incremento del siglo XVII respecto del XVI es estadísticamente significativo, $z=-3.3508, \mathrm{p}<0.05$, pero el ligero decremento del siglo posterior no lo es $(z=0.4607)$.

Los concentrados cuantitativos diacrónicos de la tabla 10 arriba aportan, en mi opinión, dos informaciones de interés histórico: una, que era importante dar la cuantificación del indio para tener la información del otro y tener un mejor control de ese 'otro', de ahí el aumento frecuencial del primero al segundo siglo, y dos, que en 
el siglo XVIII quienes necesitaban la información y tenían el control —aquellos que escribieron la documentación americana-, ya no estaban tan preocupados por cuántos eran, sino que empezaron a tener interés por quiénes eran, como se verá en la siguiente variable.

\subsection{Identificación de indio}

En este apartado analizo si la voz indio aparece o no identificada ${ }^{13}$ y cuáles eran las estrategias sintácticas más comunes para identificar los referentes aludidos mediante esta voz. Los ejemplos de (20) arriba, así como muchos otros anteriores, muestran casos de no identificación, los de (25) a continuación ejemplifican la voz indio con identificación. Como se ve en los ejemplos de (25), las estrategias de identificación son variadas: adjetivos, nombre común o nombre propio, este último en relación de aposición con la voz indio en numerosas ocasiones, una frase prepositiva adnominal, una oración de relativo, o un conjunto de las anteriores estrategias sintácticas, como en (25cef).

(25) a. y scrivjan nuevas cómo por yndios mercaderes que avian venido de Xicalango... [1525, México, CORDIAM]

b. ya que en este pueblo estando para nos alojar en el bimos vn yndio que estaua coxiendo maiz y que se queria acoxer con los demás [1531, Colombia, CORDIAM]

c. los quales dichos yndios trajeron a casa del dicho fator... don Juan Bautista yndio, governador de la parte de Santiago [1602, México, CORDIAM]

d. y que tambien descalabro con un palo a un Yndio llamado Anton Cuiba [1698, Paraguay, CORDIAM]

e. para que remitiesse a el yndio Phelipe Zupe de la nacion teguas del pueblo de Santa Clara [1704, Estados Unidos, CORDIAM]

f. aviendole antes dado el baston de cappitan mayor de toda la Apacheria a el que por tal le tenian todos, que es un yndio moso,

13 No tomo ahora en cuenta los cuantificadores, aunque gramaticalmente estos aporten también cierto tipo de identificación. 
de buen cuerpo y rostro, llamado en su lengua Yndatiyuhe, hermano de otros seis capitanes [1706, Estados Unidos, CORDIAM]

La sintaxis hasta ahora analizada ha reflejado, una y otra vez, el rango inferior del indio y la fuerte asimetría social de indios y españoles-criollos, pero la sintaxis también deja ver algunos cambios importantes hacia una mayor integración del 'otro' en la sociedad virreinal / colonial que hoy forma la actual Hispanoamérica. Hay, sin duda, diferencias cronológicas y diatópicas importantes: la asimetría social está codificada en todos los países y también la mayor progresiva identificación, pero una y otra cambian en grado y manifestación, según la profundidad histórica de los primeros poblamientos, según la intensidad de presencia indígena o según la estructura social prehispánica de las diferentes zonas americanas de habla española. Es decir, la gramática nos habla de que no es posible realizar una caracterización del 'otro' homogénea dialectalmente o carente de aristas y matices.

La tabla 11 a continuación ofrece los resultados cuantitativos de la identificación. Se desprende de él que se produjo un incremento sostenido de mayor identificación de indio, ya que, de siglo a siglo, se multiplican tres o cuatro veces las frecuencias: $7 \%>26 \%>68 \%$. El aumento es siempre significativo desde el punto de vista estadístico, al comparar cada siglo con el anterior: XVI > XVII: $\mathrm{z}=-6.2193$; XVII $>$ XVIII: $z=-10.3025, p<0.05$. El incremento de identificación indica que el indio adquirió personalidad propia y se aminoró progresivamente su conceptualización grupal indefinida. Este incremento debe ponerse en relación, sin duda, con el aumento de singular ya visto en $\$ 6.1$.

Tabla 11

Diacronía de identificación de indio

\begin{tabular}{lcc}
\hline & No identificado & Sí identificado \\
\hline XVI & $93 \%(278 / 300)$ & $7 \%(22 / 300)$ \\
xvii & $74 \%(221 / 300)$ & $26 \%(79 / 300)$ \\
xviii & $32 \%(95 / 300)$ & $68 \%(205 / 300)$ \\
\hline
\end{tabular}


Estos datos diacrónicos, a la vez que son de interés para la historia, plantean algunas preguntas y problemas de interpretación, que muestran tensiones relativas al indio, difíciles de sopesar en los documentos y los textos de prensa base del análisis. En concreto, históricamente, la alta frecuencia de la voz indio con múltiple identificación en el siglo XVIII es compleja de ser valorada. Veamos. En el siglo XVI, se documenta un solo caso con nombre propio en las primeras 300 documentaciones de indio en el CORDIAM: Melchior yndio natural de la dicha ysla (1518, Cuba); en el siglo XVIII, en cambio, aparecen muchísimas voces que acumulan estrategias, con nombre propio más adjetivos especificativos más oraciones de relativo especificativas, que logran una identificación y personalidad bien individuada, como muestran, sea por caso, (25e) y (25f) arriba. Surgen algunas preguntas inmediatamente: una, ¿la mayor identificación del indio en el siglo XVIII se debe a una mayor proximidad conceptual e integración del 'otro' en la sociedad o se debe a que el XVIII es el siglo de las taxonomías y de las clasificaciones de todo tipo y quienes escribían practicaban el gusto de describir pormenorizadamente, o ambas interpretaciones van de la mano y se complementan?; dos: ¿cómo interpretar y compaginar este incremento de identificación tan notable en el siglo XVIII con el hecho de que el indio prácticamente desaparece de la vida oficial y cotidiana en el siglo XIX?, acorde con lo visto en la tabla 2 arriba. Por ahora no tengo respuesta para ninguna de las preguntas.

\subsection{Los verbos y función gramatical de indio}

El análisis de las clases semánticas de verbos y de la función sintáctica de la voz indio en su oración arroja también información histórica de interés. En cuanto a los verbos, estos en el siglo XVI se concentran, fundamentalmente, en verbos de posesión y transferencia, como dar, vender, comprar, quitar, prender, burtar, entre otros, verbos de movimiento, como sacar, ir, venir o pasar, y el factitivo hacer, ejemplos en (26), verbos que remiten, esencialmente, junto con los contextos amplios en que se encuentran verbo e indio, a que los referentes denotados por la voz indio eran una propiedad 
más y eran la mano de obra fundamental para construir y crear los nuevos territorios, y, también, contribuir a la creación de los nuevos espacios mentales americanos. En el siglo XVIII, en cambio, se diversifican de manera notable los verbos concurrentes con indio: decir, responder, contraer, cooperar, concurrir, llegar, ir, venir, ayuntar, bajar, matar, y un largo etcétera, como se aprecia en los ejemplos de (27). La generalización de los verbos es un cambio diacrónico que apunta a un mayor dinamismo e integración del referente de indio en la sociedad americana dieciochesca, y, en general, apunta a una mayor flexibilidad y movilidad de esa sociedad.

(26) a. señalló estançias minas e jndios, a cada vno segund lo que le paresçio que se le devia dar [1520, Panamá, CORDIAM]

b. porque como lo [el oro] sacan yndios de la tierra y esclavos y aun christianos, han acostumbrado a lo fundir cada uno en su casa y aun a çendrarlo [1525, México, CORDIAM]

c. prendian a las yndias e caçiques prinçipales e los thenjan atados [1523, México, CORDIAM]

d. Del doctor Hojeda ha cohechado una mula, y asi le favoresçe en los plitos y en le dar jndios, y en todo lo demas que él quiere [1529, México, CORDIAM]

e. se ponga horden e manera como verdaderamente se pueble y por manera que las poblaçiones que se començaren permanezcan e los que en ellas poblaren o se les dieren o encomendaren yndios e los otros aprovechamientos de la tierra e otras merçedes que vuestra magestad fuere seruido de les hazer [1528, República Dominicana, CORDIAM]

(27) a. ante dicho señor comisario, paresió Domingo de Ramos, yndio ladino en la lengua castellana, yntérprete [1703, México, CORDIAM]

$\mathrm{b}$ pues aunque el dicho yndio puso espesial cuydado, nos allamos perdidos en el todo [1706, Estados Unidos, CORDIAM] c. en ellas an concurrido las naçiones de apaches, nauajoes y jutas y apaches de la xicarilla... y si concurrieron en 
ellas algunos otros yndios de los otros pueblos deste reyno, dixo que no saue [1706, Estados Unidos, CORDIAM] d. Yten declaro y dexo a los yndios del ayllo titicoleana cuatrozientos pesos en Plata en corriente [1710, Bolivia, CORDIAM]

e. estando por el mes de junio en la bentana de la cassa en que por entonses bibía el año pasado una tarde sólo en el barrio de San Francisco llegó a él un yndio de la Nueba Segovia llamado Simón Marzelo y le habló como que le conociesse [1715, Guatemala, CORDIAM]

f. En cuio tiempo el dicho Vuestro Coronel Governo esta Provincia con la madurez que âcostumbra, [...] con generales âclamaciones de los Moradores de ella, y de los Yndios, â quienes ha faborezido, âmparado y Doctrinado [1756, Nicaragua, CORDIAM]

En cuanto a la función sintáctica de la voz indio, hay también desplazamientos diacrónicos interesantes, que vuelven a ser indicativos de una mayor integración social de sus referentes en la sociedad virreinal / colonial. ${ }^{14}$ En el siglo XVI, hay más indio en función de objeto directo con el papel semántico de paciente o de objeto indirecto en papel semántico de receptor, y hay menos documentaciones de indio en función de sujeto, además de que cuando tienen esta función, la voz suele aparecer como un sujeto poco agentivo, inacusativo, pospuesto al verbo, próximo por ello al significado paciente del objeto directo; varios de los ejemplos de (26) y otros muchos de los siglos XVI y XVII vertidos en este trabajo, confirman tales preferencias sintáctico-semánticas. En el siglo XVIII, en cambio, el indio aparece más en función de sujeto agente o de complemento circunstancial, además de que es notorio que los referentes de indio

\footnotetext{
14 Es sabido que no todos los territorios americanos estuvieron bajo la jurisdicción de un virreinato y ni siquiera de una audiencia, tal es el caso, por citar uno entre muchos, de Cuba; por ello, escribo virreinal / colonial, para no entrar en este momento en diferencias conceptuales de indio según el tipo de estatus administrativo jurídico del territorio en cuestión.
} 
tienen voz, el dicho indio dixo, y que se pueden mover y desplazar en los ámbitos espaciales en que ellos vivían, fueron los dichos indios a, apareció dicho indio, como muestran varios de los ejemplos de (27) y otros de este trabajo correspondientes a esta centuria.

En general, el cambio más notable en este apartado es que se modifican los contextos amplios y temas en que aparece la voz, cambios cuyos protagonistas gramaticales fundamentales son el tipo semántico de verbo y la relación que la voz indio contrae con aquel. El proceso de cambio, grosso modo, fue el siguiente: de aparecer la voz indio en contextos que pueden ser calificados de negativos, en cuanto que plasman una perspectiva negativa del 'otro' y lo ubican en un rango social muy inferior, se pasa a contextos que pueden ser calificados de menos negativos o neutros, e incluso, ocasionalmente, cercanos y positivos del indio, contextos construidos, claro está, desde la perspectiva del escritor del documento o texto en cuestión.

\section{Conclusiones}

Hemos visto que la ideología asociada a la voz indio se hace patente o está latente en la documentación y prensa americanas escritas entre 1494 y 1905, y ello es lógico porque hablar o escribir es una actividad transversal a todas las facetas de la vida diaria de cualquier ser humano.

La finalidad de este trabajo ha sido arrojar luz a la historia de los conceptos cobijados bajo la voz indio desde el análisis de la lengua y de la gramática. Para ello, hemos estudiado esta voz a lo largo de una historia de 400 años, desde diferentes ángulos gramaticales y textuales, a partir de un corpus histórico americano, el CORDIAM, que contiene varios miles de documentos de archivo y algunos miles de textos de prensa que abarcan desde finales del siglo Xv hasta el inicio del siglo xx. Este corpus proporciona datos cuantitativos inmediatos que son un soporte empírico sólido para las generalizaciones planteadas y permite medir la significatividad estadística de las evidencias encontradas. Como todo corpus de lengua, es un corpus multidisciplinario, y por ello es posible analizar un 
fenómeno, una voz en este caso, desde muchas perspectivas. Hemos visto que no existe una relación unitaria ni simple entre ideología, cultura y lengua, sino que este vínculo es multiangular y complejo, al menos cuando se aborda la voz indio.

Hemos constatado que el indio es 'el otro' desde 1492, y sigue siendo 'el otro' en la mayoría de actuales países de Hispanoamérica, un 'otro', incluso, en zonas de fuerte presencia indígena con lenguas amerindias vivas. Hemos comprobado que existe una presencia constante de indio en la vida cotidiana desde las primeras llegadas de españoles, pero hemos comprobado también que la presencia documental de indio se adelgaza cuando nos aproximamos al siglo XIX y prácticamente desaparece de la vida escrita en el periodo de las independencias. Los textos analizados y los ángulos gramaticales abordados muestran tensiones ideológicas y cambios de conceptualización de la voz indio y de sus referentes, por parte de quienes escribieron y narraron la vida americana de 1494 a 1905.

Los principales cambios con significatividad estadística fueron los siguientes: fuerte asociación a cierto tipo de documentos y soportes textuales; pronta adscripción al sistema estratificado de castas; fuerte contraste y rango social inferior cuando se compara con la voz español y se observa el tratamiento de respeto don para indio y para quienes no lo eran; una mayor individuación y mayor identificación de los referentes aludidos con la voz indio; diversificación de verbos, y, en general, un cambio de perspectiva en el contexto amplio, negativa > menos negativa.

El indio aparece conceptualizado en los documentos desde muchas perspectivas, mayormente negativas: como nativo - muchos menos ejemplos de los esperados-, como mano de obra, como desprotegido, como clase y casta inferior, como intérprete, como guía de expediciones, y se documenta una constante a lo largo de todo el corpus en términos de asimetría social y de tutelaje de quienes controlaron la administración hacia el 'otro'.

Surgieron a lo largo del trabajo algunas preguntas relativas a si los cambios registrados, particularmente en el siglo XVIII, fueron verdaderos cambios conceptuales relativos a los referentes de la voz 
indio, a su vida en la sociedad americana y a su relación con los actores que escribieron la vida en América. Las posibles respuestas serán motivo de nueva investigación y trabajo.

\section{Referencias bibliográficas}

\section{Academia Mexicana de la Lengua (aml)}

2010 Diccionario de mexicanismos. México: Siglo XXI Editores.

s/f Corpus Diacrónico y Diatópico del Español de América (CORDIAM). Consultado: s/f. <www.cordiam.org $>$.

Alberro, Solange y Pilar Gonzalbo

2013 La sociedad novohispana. Estereotipos y realidades. México: El Colegio de México.

Asociación de Academias de la Lengua Española (asale)

2010 Diccionario de americanismos. Madrid: Santillana.

Bertolotti, Virginia y Concepción Company Company

2014 "El Corpus Diacrónico y Diatópico del Español de América (CORDIAM). Una propuesta de tipología textual”. En El español en América. Corpus y textos. Cuadernos de Lingüistica (ALFAL). Eds., Claudia Parodi y Micaela Carrera de la Red. Consultado: s/f. <http://74.200.74.244/ munadmin/>.

2018 "El corpus para América: cordiam”. En Léxico y bumanidades digitales. Eds., D. Corbella, A. Fajardo e I. Klanz. Zurich: Peter Lang.

Company Company, Concepción

1995a "Cantidad vs. cualidad en el contacto de lenguas. Una incursión metodológica en los posesivos redundantes del español americano". Nueva Revista de Filología Hispánica. 43, 2, 305340.

1995b "Old forms for new concepts. The recategorization of possessive duplications in Mexican Spanish". En Historical Linguistics 1993. Ed., Henning Andersen. Amsterdam: John Benjamins, 77-93.

2007 El siglo XVIII y la identidad lingüistica de México. México: Universidad Nacional Autónoma de México y Academia Mexicana de la Lengua. 
2012 “Indigenismos, identidad e Independencia”. En Coloquio Testigos y Actores de la Historia. Independencia y Revolución en la Biblioteca y Hemeroteca Nacionales. Número monográfico del Boletín del Instituto de Investigaciones Bibliográficas. México: Universidad Nacional Autónoma de México. 15, 109-120.

Dirven, René, Bruce Hawkins y Esra Sandikcioglu (eds.)

2001 Language and ideology. Amsterdam: John Benjamins.

FERES JÚNIOR, João

2009 "El concepto de América en el mundo atlántico (1750-1850). Perspectivas teóricas y reflexiones sustantivas a partir de una comparación de múltiples casos". En Diccionario político $y$ social del mundo iberoamericano. La era de las revoluciones 1750-1850 (Iberconceptos-I). Dir., Javier Fernández Sebastián. Madrid: Fundación Carolina, Sociedad Estatal de Conmemoraciones Culturales y Centro de Estudios Políticos y Constitucionales, 51-67.

FERnÁNDEZ Sebastián, Javier

2009a Diccionario político y social del mundoiberoamericano. La era de las revoluciones 1750-1850 (Iberconceptos-I). Dir., Javier Fernández Sebastián. Madrid: Fundación Carolina, Sociedad Estatal de Conmemoraciones Culturales y Centro de Estudios Políticos y Constitucionales.

2009b "Introducción. Hacia una historia atlántica de los conceptos políticos”. En Diccionario político y social del mundo iberoamericano. La era de las revoluciones 1750-1850 (Iberconceptos-I). Dir., Javier Fernández Sebastián . Madrid: Fundación Carolina, Sociedad Estatal de Conmemoraciones Culturales y Centro de Estudios Políticos y Constitucionales, 23-48.

HAWKINS, Bruce

2001 "Tensions. On the treatment of ideology in cognitive linguistics". En Language and ideology. Eds., René Dirven, Bruce Hawkins y Esra Sandikcioglu. Amsterdam: John Benjamins, 1-23.

Hodge, Robert y GunTHER Kress

1993 Language as ideology. London: Routledge.

JAKOBSON, Roman

1939/1971 “Signe zéro”. En Selected writings, vol. 2. R. Jakobson ParisLa Haya: Mouton, 211-222. 
León-Portilla, Miguel

1993 “Alteridad: tutela y transformación”. En De palabra y obra en el Nuevo Mundo. Vol. 3: La formación del otro. Eds., Gary H. Gossen, Jorge Klor de Alva, Manuel Gutiérrez Estévez y Miguel León-Portilla. Madrid: Siglo XXI de España Editores, 5-30.

2011 Independencia, Reforma, Revolución, ¿y los indios qué?. México: Consejo Nacional para la Cultura y las Artes y Universidad Nacional Autónoma de México.

Marichal, Carlos

2017 "Un capítulo olvidado del comercio internacional: la grana cochinilla mexicana y la demanda europea de tintes americanos, de 1550-2000". En De la plata a la cocaina. Cinco siglos de historia económica de América Latina, 1500-2000. Eds., Carlos Marichal, Steven Topik y Zephyr Frank. México: El Colegio de México y Fondo de Cultura Económica.

Mazín, Óscar

1999 "De los indios a los indígenas: procesos de transformación”. Relaciones, 78, 10-15.

Obara-Saeki, Tadashi y Juan Pedro Viqueira Alban

2017 El arte de contar tributarios. Provincia de Chiapas 1560-1821. México: El Colegio de México.

Ramírez Zavala, Ana Luz

2011 “Indio / Indígena, 1750-1850”. Historia Mexicana, 60, 3, 1643 1681.

Real Academia Española (Rae)

1726-1739/1990 Diccionario de Autoridades. Edición facsímil. Madrid: Gredos.

s/f Corpus Diacrónico del Español (CORDE). Consultado: s/f. $<$ www.rae.es $>$.

Real Academia Española y Asociación de Academias de la Lengua Española (RAE-Asale)

2013 Diccionario de la lengua española. Madrid: Espasa.

Silverblatt, Irene

1993 "El surgimiento de la indianidad en los Andes del Perú central: el nativismo del siglo XVII y los muchos significados de 
'indio'”. En De palabra y obra en el Nuevo Mundo, vol. 3: La formación del otro. Eds., Gary H. Gossen, Jorge Klor de Alva, Manuel Gutiérrez Estévez y Miguel León-Portilla. Madrid: Siglo XXI de España Editores, 459-482.

TAYLOR, William B.

1989 “...'de corazón pequeño y ánimo apocado’. Conceptos de los curas párrocos sobre los indios en la Nueva España del siglo xviii”. Relaciones, 39, 5-66.

Recepción: 21/01/2019

Aceptación: 08/04/2019 